\title{
Physiotherapy in small animal medicine
}

\author{
Fysiotherapie bij kleine huisdieren
}

\begin{abstract}
Y. Samoy, B. Van Ryssen, J. Saunders
Department of Medical Imaging and Small Animal Orthopedics, Faculty of Veterinary Medicine, Ghent University, Salisburylaan 133, B-9820 Merelbeke
\end{abstract}

Yves.samoy@UGent.be

\begin{abstract}
$\Lambda_{\text {bstract }}$
The benefits of physiotherapy have been extensively demonstrated in human medicine. Although physiotherapy has been performed in veterinary medicine for already several decades, it is only very recently that scientific research on this subject is increasing. The purpose of this paper is to give an overview of the different veterinary physiotherapeutic assessment and treatment techniques and possibilities, and correlate them to the data in the veterinary literature.
\end{abstract}

\section{SAMENVATTING}

De voordelen van fysiotherapie zijn reeds lang bekend in de humane geneeskunde. Ook in de diergeneeskunde wordt de therapie reeds enkele decennia toegepast, maar het is pas vrij recentelijk dat er ook wetenschappelijk onderzoek naar verricht wordt. Het doel van dit artikel is een overzicht te geven van de verschillende fysiotherapeutische mogelijkheden en technieken in de diergeneeskunde en deze te correleren aan de bevindingen die te vinden zijn in de literatuur.

\section{INTRODUCTION}

The benefits of physiotherapy in human medicine have been known for many decades and nowadays, it has been incorporated in the plan of care of conditions, like cruciate ligament rupture (Anderson and Lipscomb, 1989; Shelbourne and Nitz, 1990; Shelbourne et al., 1991), fracture repair (Kristiansen et al., 1997; Sherrington and Lord, 1997; Diong et al., 2015), joint arthroplasty (Moffet et al., 2004; Denis et al., 2006), spinal surgery (Ostelo et al., 2003; Ostelo et al., 2009) osteoarthritis (OA) (Dias et al., 2003), lower back pain (Aure et al., 2003) and many other conditions (Levine et al., 2005). Although physiotherapy has been used over twentyfive years in veterinary medicine (Prydie and Hewitt, 2015) and several studies have been published on how to perform animal physiotherapy (Bockstahler et al., 2004; Zink and Van Dyke, 2013; Millis and Levine, 2014), in the veterinary literature, physiotherapy is poorly documented.

The goal of this paper is to review the veterinary physiotherapeutic possibilities and to explore what is known on the effect of animal physiotherapy in the literature.

\section{THE GOALS OF PHYSIOTHERAPY}

Independent of the species, the goals of physiotherapy are always the same (Levine et al., 2005; Sharp, 2008): reduce pain, facilitate healing, increase (or maintain) muscle strength, restore normal osteokinematic and artrokinematic movement of joints, increase the general condition and restore normal functionality.

Based on the findings on physiotherapeutic assessment (symmetry, kinematics, end feel, flexibility, translation, etc.), the physiotherapist can choose out of three therapeutic categories to achieve these goals (Prydie and Hewitt, 2015). They can either be used separately or in combination. The first category is manual therapy. This therapy includes all techniques that involve the use of the hands of the physiotherapist. It is mainly used to reduce pain and help with loss of motion secondary to neuromusculoskeletal disorders (Saunders et al., 2005). The second category is the use of therapeutic modalities. It involves every technique, in which an external energy source is used to stimulate or support the healing process (Prydie and Hewitt, 2015). The third category consists of therapeutic exercises. 
This category holds every exercise that actively trains the muscles and improves the mobility of the joints. These exercises also help in training coordination, proprioception and core stability. In a later stage, they are indispensable to train muscles and improve cardiorespiratory fitness. (Prydie and Hewitt, 2015). A lot of these exercises are part of the home exercise program. Owners should continue to revalidate/train their pet at home using the guidelines given by the physiotherapist. As it is a very important part in physiotherapy, good instructions on how to perform the exercises are required (Prydie and Hewitt, 2015).

\section{MANUAL THERAPY}

Manual therapy is a term that covers all soft tissue techniques used in (animal) physiotherapy with the intention to soothe pain, improve tissue extensibility, increase range of motion (ROM), change muscle tension (relax or stimulate), manipulate soft tissue and joints, reduce swelling and inflammation and improve the general circulation (Zink and Van Dyke, 2013). Manual therapy principally consists of soft tissue mobilization (i.e. massage), joint mobilization and passive movement (pROM) (i.e. cycling movements). Although the techniques of different types of manual therapy are well described in the veterinary literature, to date, only limited information can be found regarding clinical results in animals (Bockstahler et al., 2004; Saunders et al., 2005; Zink and Van Dyke, 2013; Prydie and Hewitt, 2015). Most references are based on data found in the human literature and provide controversial and limited documentation on soft tissue mobilization (Hertling and Kessler, 2006; Zink and Van Dyke, 2013). Studies on joint mobilization and pROM show positive effects in humans, but research lacks in veterinary medicine (Landrum et al., 2008; Zusman, 2010). Although the principles are similar, straight forward interspecies extrapolation should be treated carefully. In one study, massage was actively incorporated in the physiotherapeutic protocol of dogs with degenerative myolopathy, besides active and passive exercises and hydrotherapy (Kathmann et al., 2006). This report demonstrates that intensive physiotherapeutic treatment may prolong the life expectancy by factor five compared to dogs without physiotherapy. However, the study design could have biased this result, as the owners were involved in the group selection.

\section{THERAPEUTIC MODALITIES}

Therapeutic modalities use physical forces, such as temperature, electric current, sound and light to create an effect on tissue. Each of these modalities are discussed below.

\section{Temperature}

The use of temperature changes is one of the oldest forms of physiotherapy and is easily accessible to veterinarians and owners (Olson and Stravino, 1972; Millis and Levine, 2014). The purpose of heat and cold treatment is to decrease pain, reduce swelling, improve flexibility and promote overall healing. The principle is based on universal physiologic cell reactions. Cold induces vasoconstriction decreases blood flow, muscle spasm and tissue swelling, reduces metabolism and enzyme-mediated tissue damage and gives analgesia by decreased nerve conduction velocity. Heat has the opposite effect. It induces vasodilatation and leukocyte migration, increases the blood flow, soft tissue extensibility and metabolism, relaxes muscles and reliefs pain (Michlovitz, 1996; Millis and Levine, 2014).

\section{Cold}

A study by Bocobo et al. (1991) investigated the optimal application of cryotherapy in the dog. Icepacks were used on the stifle joint for 5,15 or $30 \mathrm{mi}-$ nutes and intra-articular as well as rectal core temperatures were noted. A linear drop of intra-articular temperature was noted with a longer period of cooling. The core temperature was minimally affected up to 15 minutes of treatment $\left(0.1^{\circ} \mathrm{C}\right)$. Thirty minutes of cooling resulted in a further $0.5^{\circ} \mathrm{C}$ drop of core temperature. The effect of cooling remained for another 21.7 to 33.2 minutes. The use of ice water emersion resulted in a much higher temperature drop both in intra-articular and in core temperature, and in a longer lingering effect of approximately one hour (Bocobo et al., 1991). Wakim et al. (1951) found that using icepacks on the canine stifle for more than 30 minutes does not cause additional effect. Therefore, it can be concluded that the optimal duration of local cryotherapy on the canine stifle, with minimal effect on the core temperature, is 15 to 30 minutes, with an ideal of 20 minutes (Millard et al., 2013). For optimal effect, this treatment is to be repeated two to four times a day (Millis, 2004).

The effect of cryotherapy on the stifle has been investigated in two studies. In one study, it could be demonstrated that postoperative tissue swelling after extracapsular stifle surgery decreased significantly more when using icepacks (all or not combined with bandaging), than with the use of bandaging alone (Rexing et al., 2010). In the other study, the effects of cryotherapy after tibial plateau levelling osteotomy (TPLO) were described. A significant lower pain score, lower lameness score, less swelling and better ROM in the first 24 hours after surgery were demonstrated (Drygas et al., 2011).

\section{Heat}

The easiest way to apply heat to the body is to use superficial agents such as hot packs (Millard et al., 2013; Millis and Levine, 2014). Heat can either be used on soft tissues that entered the healing phase (48 hours post trauma at the earliest) or in cases of chronic pain (Millis, 2004; Millard et al., 2013). However, no scientific data on the ac- 
tual healing effect of heat in small animal medicine can be found to date (Millard et al., 2013). Besides the purely healing effect, heating soft tissues also has another function. When applying heat prior to stretching and exercise, it might cause less tissue damage and a larger ROM (Millis, 2004; Millis and Levine, 2014), facilitating other physiotherapeutic exercises. A recent study on the heating effect of warm compresses on the lumbar region in dogs demonstrated that a 10 -minutes application of a $47^{\circ} \mathrm{C}$ compress resulted in a $4.14^{\circ}$ increase at $0.5 \mathrm{~cm}$ depth, $2.2^{\circ}$ increase at $1 \mathrm{~cm}$ depth and $0.58^{\circ}$ at $1.5 \mathrm{~cm}$ depth. Core temperature was not affected. Shorter application resulted in lower increase of temperature, longer application did not show significant increase of temperature. Studies on the duration of the heating effect are not available to date (Millard et al., 2013).

To heat deeper structures up to $5 \mathrm{~cm}$, external heat compresses are not sufficient. Other modalities such as continuous ultrasonography or infrared/laser should be considered (Millis, 2004; Steiss and Levine, 2005).

\section{Electric current}

Electrical stimulation in small animal physiotherapy has mainly been used with the intention to ease pain or to stimulate the muscle and/or nerve function (Bockstahler et al., 2004; Steiss and Levine, 2005; Zink and Van Dyke, 2013; Prydie and Hewitt, 2015). In veterinary medicine, devices used for electrical stimulation are generally small portable units powered by a nine-volt battery. The device has either one or two power cords leading to the electrodes (Figure 1). The better equipped devices both have a pain reduction and muscle stimulating function.

\section{Transcutaneous Electrical Nerve Stimulation (TENS)}

This is a type of electrical stimulation especially used for pain control (Bockstahler et al., 2004). The principle of TENS is based on the Gate Control Theory, that proposes a mechanism in the dorsal horns of the spinal cord that acts like a gate that can either inhibit or facilitate transmission from the body to the brain on the basis of the diameters of the active peripheral fibres, as well as the dynamic action of brain processes (Melzack and Wall, 1965) (Figure 2). Neural systems have three important types of fibres (Bockstahler et al., 2004):

- A $\beta$ fibres are fast transmitting fibres for vibration and pressure sensation.

- $\mathrm{A} \delta$ and $\mathrm{C}$ fibres are slow transmitting fibres conducting pain signals.

- Substania gellatinosa (SG) cells inhibit the pain signal to the brain.

By overstimulating the A $\delta$ and $\mathrm{C}$ fibres, SG cells get activated and the pain signal is blocked. In other words, the brain receives an overload of information, resulting in a blocked transmission of pain signals (Fox, 2013).
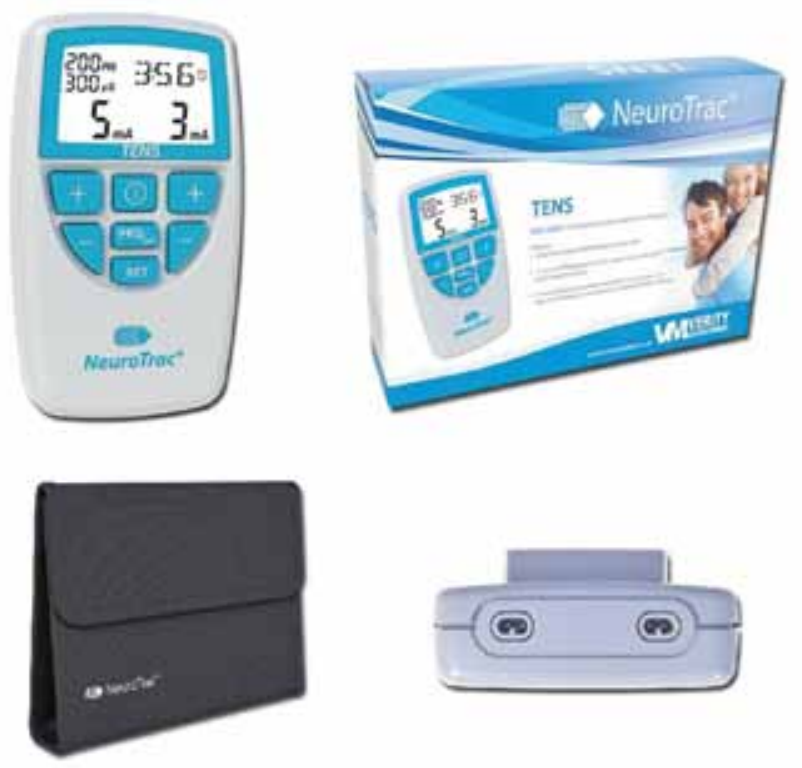

Figure 1. Neurotrac ${ }^{\circledR}$ TENS/NMES device.

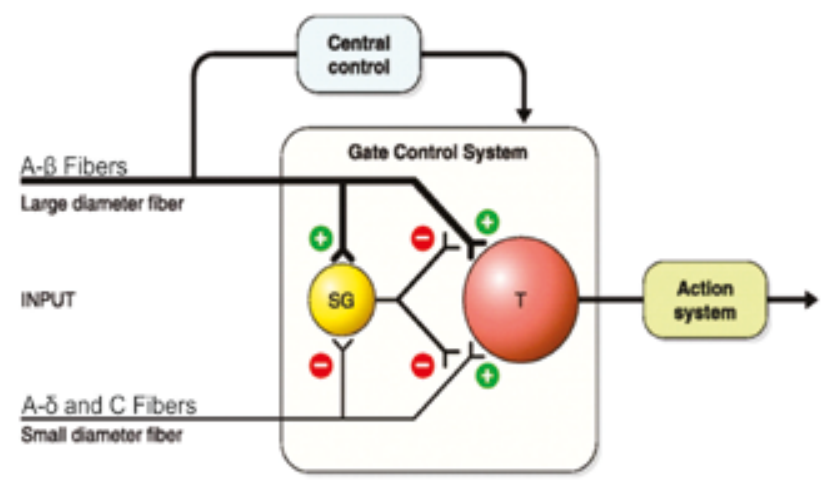

Figure 2. Gate control theory (Adapted from Zeilhofer et al., 2012)

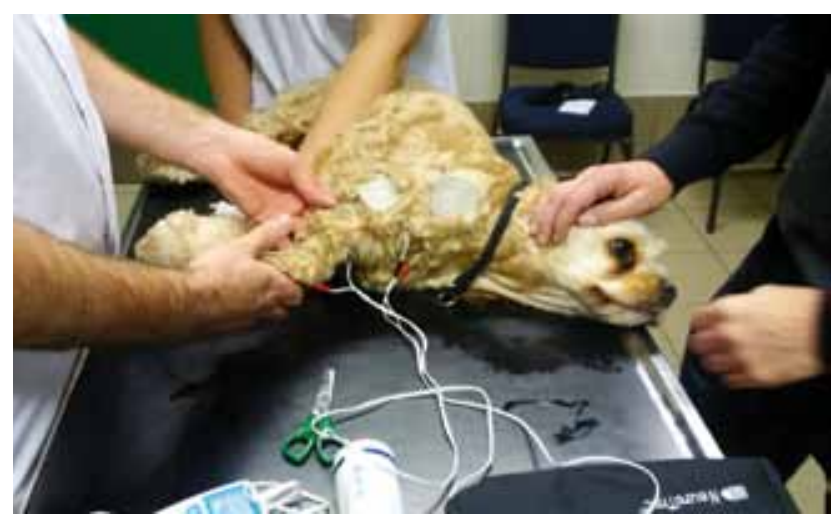

Figure 3. The use of NMES on the front leg of a dog.

TENS has been demonstrated efficient in orthopedic and neurologic conditions in humans, but research in the veterinary field is still limited (Millis and Levine, 2014). In one study, the effect of TENS on five osteoarthritic canine stifle joints was evaluated using force plate evaluation. A significantly improved weight bearing could be demonstrated, starting from 
30 minutes until 210 minutes after treatment, with a peak improvement at 30 minutes (Levine and Millis, 2002).

Mlacnik et al. (2006) investigated the possible benefit of TENS combined with a weight loss program in dogs with several types of lameness. It was observed that dogs that had TENS not only lost weight faster than dogs without TENS, but also showed better weight bearing (validated by force plate) than the other group (Mlacnik et al., 2006).

\section{Neuro muscular electrical stimulation (NMES)}

NMES indicates that electrical current is used to stimulate a muscle or nerve using an intact nerve (Bockstahler et al., 2004). Giving an electrical impulse to the neuromuscular unit results in an initial contraction of the faster type II muscle fibres, followed by contraction of the slower type I muscle fibres (Figure 3 ). The power of an NMES induced muscle contraction is lower than that of a voluntary muscle contraction, but often, a maximal voluntary muscle contraction is impossible or undesired after injury or surgery. In those cases, NMES can help to maintain or revalidate the muscle function (Steiss and Levine, 2005; Millis and Levine, 2014).

NMES has been used in a series of orthopedic and neurologic conditions in humans and has become standard plan of care in many conditions (Millis and Levine, 2014). Data in the veterinary literature are scarce but promising. In an experimental study in dogs, Johnson et al. (1997) demonstrated a significantly greater thigh circumference, an improved subjective lameness score and a lower degree of osteoarthritis. Millis and Levine (2014) investigated the difference in revalidation between ten dogs that had lateral suture surgery for cranial cruciate ligament (CCL) rupture. Five of the dogs received standard postoperative care consisting of rest and leash walks while the other five received additional $\mathrm{ROM}$ and walking exercises combined with NMES. A significantly greater thigh circumference and ROM were noted in the exercise group than in the group of dogs that received standard postoperative care (Millis and Levine, 2014).

Because electrical pulses are generated to pass through tissues, animals with cardiac problems or pace makers should not receive NMES treatment. The therapy is also contraindicated in animals with a history of seizures.

\section{Soundwaves}

\section{Therapeutic ultrasound}

In therapeutic ultrasound (US), energy created by vibration of a piezoelectric crystal is used. Due to an electrical current, the crystal starts to vibrate and creates ultrasonic sound waves (Figure 4). The frequency of the waves depends on the electrical current sent through the crystal. The amount of energy or intensity carried by the soundwave corresponds with the amplitude and is usually measured in Watt per $\mathrm{cm}^{2}$ (Bockstahler et al., 2004).

Sound waves migrate easily in an aquatic environment and are attenuated in an air environment. Therefore, hair should be clipped and a water based medium, such as water-soluble ultrasound gel, should be

\section{Electrical Characteristics}

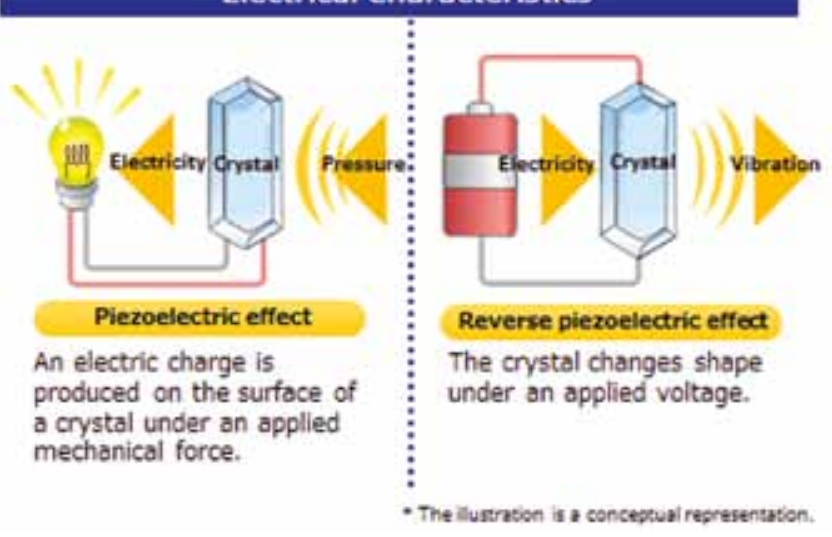

Figure 4. Mechanism of a piezoelectric crystal (Source: Global Epson).

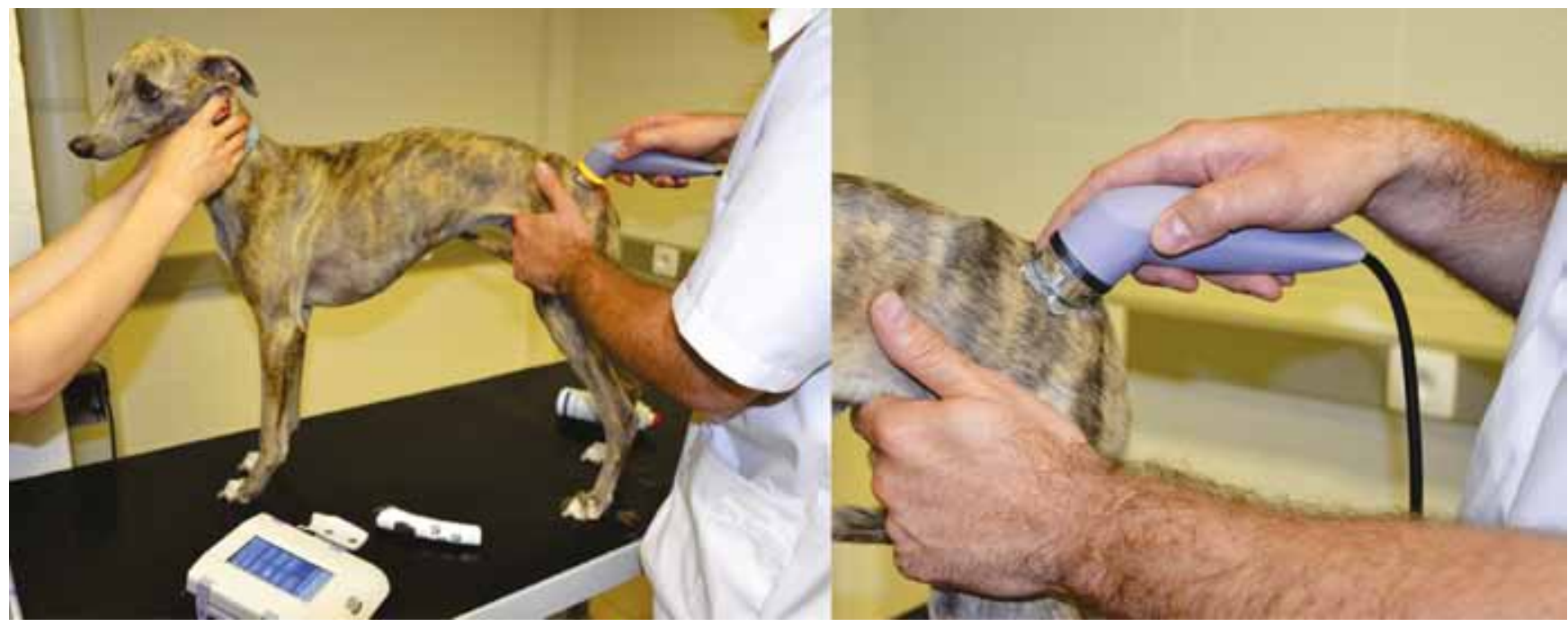

Figure 5. Use of ultrasound on the stifle of a dog. 
used to accommodate the energy transfer (Millis and Levine, 2014) (Figure 5). Energy absorption is higher in tissues with high protein content. In terms of tissue types, this results in (low to high absorption) blood, fat, muscle, blood vessels, skin, tendon, cartilage and bone.

The effect on tissues depends on the type of ultrasound that is used: continuous wave $(\mathrm{CW})$ ultrasound generates a continuous stream of energy, resulting in a tissue heating effect. In pulsed wave (PW) ultrasound, the energy stream is intermittently on and off. The latter mode is used when non-thermal effects are desired (Bockstahler et al., 2004; Prydie and Hewitt, 2015).

\section{Continuous wave (CW)}

This application was the initial goal of ultrasonographic therapy. Tissue heating is claimed to have an influence on a variety of conditions such as, increased collagen extensibility, blood flow, nerve conduction, enzyme activity and decrease in pain sensation. The depth of the heating effect is determined by frequency and amplitude. Most devices have 1MHz- and $3 \mathrm{MHz}$-frequency settings. $1 \mathrm{MHz}$ Frequency delivers heat at a depth of 2 to $5 \mathrm{~cm}, 3 \mathrm{MH}$ frequency between 0.5 and $3 \mathrm{~cm}$ of depth. The higher the amplitude, the more energy is delivered, the higher and faster the temperature increases (Millis and Levine, 2014).

In a study with ten dogs, a $3 \mathrm{MHz}$ probe was used to induce an increase of temperature in the thigh muscles. The difference in temperature was measured using heat sensitive needles at 1,2 and $3 \mathrm{~cm}$ of depth. Depending on the intensity, an increase up to $4.6^{\circ} \mathrm{C}$, $3.6^{\circ} \mathrm{C}$ and $2.4^{\circ} \mathrm{C}$, respectively, could be demonstrated. This effect remained present for about ten minutes (Levine et al., 2001).

It can be concluded that $\mathrm{CW}$ ultrasound is useful for heating tissue to at least $3 \mathrm{~cm}$ of depth and that an increase of amplitude results in an increase of tissue temperature.

\section{Pulsed wave (PW)}

Contrary to $\mathrm{CW}$, the aim of PW is not to heat the tissue but to deliver energy to the deeper tissues. This energy can be used to repair either soft tissue or bone. Looman et al. (2003) demonstrated that PW does not have a thermal effect. In their US study on tendon tissue, they found that the thermal effect of PW is significantly lower (increase of temperature lower than $1.5^{\circ} \mathrm{C}$ ) than in case of CW. Contrary to what is seen in the $\mathrm{CW}$, the increase of intensity gave no significant increase in the temperature of the tendon tissue (Loonam et al., 2003).

Pulsed wave ultrasonography aids in the modulation of the inflammatory process (Millis and Levine, 2014). By stimulating the platelets, neutrophils, macrophages and causing mast cells to degranulate, the inflammatory cascade is facilitated (Maxwell, 1992). Therefore, the inflammation period should run smoother and faster.
In human medicine, PW is used for several soft tissue conditions, with good result. The main indications in humans are tendinitis, bursitis, joint contracture, pain, muscle spasms and treating of scar tissue (Millis and Levine, 2014). Reports on soft tissue repair are scarce in the veterinary literature. There is one study on rats and one on rabbits investigating muscle trauma and ear trauma, respectively, but without any hard evidence of effects on long term. In the acute phase, PW would be beneficial (Dyson et al., 1968; Rantanen et al., 1999). Although it is most likely that animals also benefit from PW, it has yet to be proven.

More research has been performed on bone repair. Several studies in rats and dogs have demonstrated a beneficial effect of PW in the acute phase of bone healing, and even in the process of delayed- and non-union (Zorlu et al., 1998; Rantanen et al., 1999; Tanzer et al., 2001; Rawool et al., 2003; Rodrigues et al., 2004; Schortinghuis et al., 2004; de Sousa et al., 2008; Favaro-Pipi et al., 2010; Mosselmans, 2011; Mosselmans et al., 2013; Toy et al., 2014).

\section{Shockwave}

Shockwave therapy is based on the creation of high pressure and high velocity soundwaves that are sent through the skin to the desired location. Based on the density of the tissue, more or less energy is released. The main differences between ultrasound and shockwave therapy is that the latter does not induce heat, has a lower frequency and minimal tissue absorption (Millis and Levine, 2014).

The limited studies that are available in small animal veterinary medicine focus on pain relieve in dogs with osteoarthritis (OA) of the hip (Mueller et al., 2007), OA of the stifle (Dahlberg et al., 2005) and dogs with patellar desmitis post-TPLO (Gallagher et al., 2012). In all of the studies, a positive effect of shock wave therapy was reported, although significant changes were only noted in the studies on hip OA and patellar desmitis. The positive effect of shockwave therapy on $\mathrm{OA}$ in elbows was demonstrated in fifteen dogs (Millis et al., 2011).

The effect of shockwave therapy on soft tissues, tendons, ligaments and wound healing has mostly been examined in laboratory animals, serving as a human model. Positive effect has been demonstrated, but up till now, data on dogs are not available. Preliminary results on the effect of bone healing post TPLO are promising but need to be further investigated on fractures or delayed union (Kieves et al., 2015).

Because of the intensity of the waves, shockwave is not indicated in case of neoplasia, acute inflammation, recent surgery, presence of implants, unstable fractures, neurologic deficits, immature animals and coagulation disorders (Bockstahler et al., 2004; Millis and Levine, 2014).

Although promising effects were demonstrated on OA, wound healing, fracture and ligament healing, more research in the canine field is necessary to estimate the real value of shockwave therapy. 


\section{Light Therapy}

For many centuries, healing effects have been attributed to light. Over the last years, laser (i.e. light amplification by stimulated emission radiation) therapy has become increasingly popular for the treatment of a variety of conditions. For physiotherapeutic purposes, there are two main groups: cold lasers or low level laser therapy (LLLT) and therapeutic lasers (Millis and Levine, 2014). The classification of the laser devices is based on their power. LLLT lasers are classified as Class 3 and have a wavelength up to 500 milliwatts $(\mathrm{mW})$, while the more powerful therapeutic lasers are classified as Class 4 (higher than $500 \mathrm{~mW}$ ) (Prydie and Hewitt, 2015). A more detailed description on the classification of lasers is not subject of this review and can be found on the website of the American National Standards Institute (ANSI).

The effect of laser is based on the emission of different wavelengths that are absorbed by the chromophores in different types of tissues. Each tissue has a different concentration of chromophores and the wavelength of the laser influences the absorption by the chromophores (Millis and Levine, 2014). The physiotherapeutic effect of laser therapy may vary, depending on the type of tissue and the different wavelengths of the laser.

Wavelengths under 600 nanometre $(\mathrm{nm})$ are mostly absorbed and scattered by melanin and hemoglobin, and thus have little biologic effect. Wavelengths over $1400 \mathrm{~nm}$ are absorbed by water, and again have no biologic effect. Therefore, the optimal wavelength for therapeutic lasers should be between 600 and $1200 \mathrm{~nm}$ (Figure 6).

The wavelength also influences the depth of penetration. Longer wavelengths penetrate deeper (up to $2 \mathrm{~cm}$ direct penetration and $5 \mathrm{~cm}$ indirect penetration) than shorter wavelengths. Therefore, lasers with shorter wavelengths may be used for superficial injuries, while lasers with a longer wavelength may work deeper. Studies on skin penetration have mainly been performed on human skin (Kolarova et al., 1999; Esnouf et al., 2007). The effect of the skin composition and coat of animals on the penetration is currently unknown.

The power of a laser influences treatment time more than it influences the effect of the therapy. The power of a laser is expressed in watts (W). The energy delivered by a laser is expressed in joules $(\mathrm{J})(=$ watt $\mathrm{x}$ seconds) per $\mathrm{cm}^{2}$. Therefore, the higher the power of a laser (W), the less time is needed to deliver the same amount of energy $(\mathrm{J})$. For example, a laser with double power will need half the time for the same effect (Figure 7).

The most frequently advocated indications for laser therapy are wound healing and pain management, although scientific proof is scarce and is often based on in vitro models (Millis et al., 2005).

Studies that involve life animals are limited to laboratory animal studies and reveal carefully positive results concerning wound healing, especi-

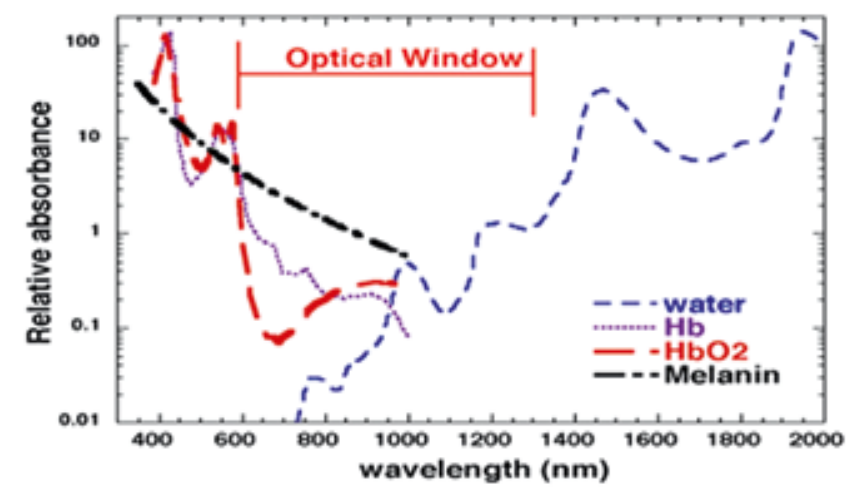

Figure 6. Optimal wavelength in LASER treatment. $\mathrm{Hb}=$ Hemoglobin; HbO2= Oxygenated Hemoglobin (Source: www.spie.com)

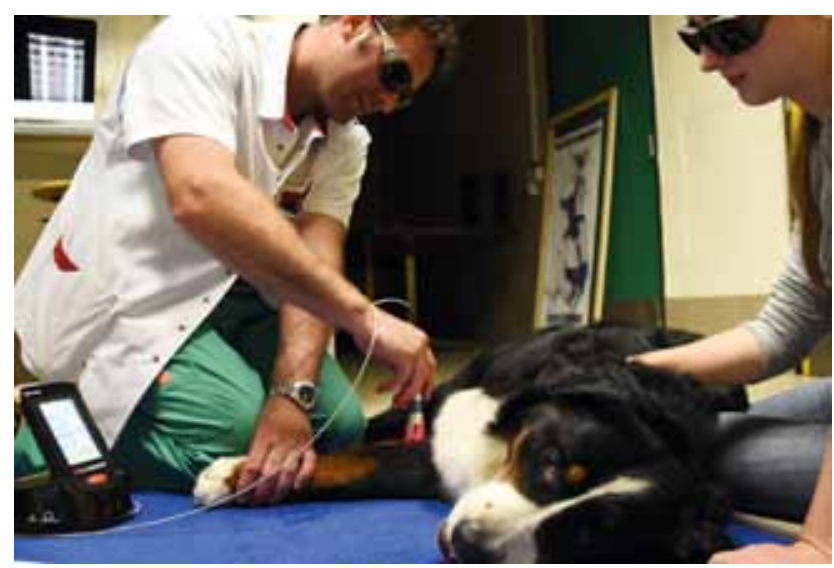

Figure 7. Laser therapy in a dog with chronic elbow arthritis.

ally in the early phase of healing (Braverman et al., 1989; Rezende et al., 2007; Peplow et al., 2010). Laboratory animals have also been used to examine the effects of LLLT on bone healing. Most of these studies have demonstrated a (mild) positive effect when laser therapy was used either alone or in combination with another modality (Pinheiro et al., 2000; Lirani-Galvao et al., 2006; Gerbi et al., 2008). The therapy has shown to be most effective in the early stage of bone healing. (Pinheiro et al., 2000; Queiroga et al., 2008; Batista et al., 2015) Where US therapy is believed to have its optimal effect on bone resorption, LLLT is believed to be responsible for an optimization of bone formation (Lirani-Galvao et al., 2006). The effect on cartilage is dual. Laser therapy shortly after cartilage damage might induce better healing of the lesion (Guzzardella et al., 2000; Morrone et al., 2000; Guzzardella et al., 2001), but there are also indications that it might protect the quality of the cartilage during periods of disuse and immobilization (Akai et al., 1997; Bayat et al., 2004). Whether these effects are similar in other animals is still to be determined.

Several studies in humans and animals have demonstrated that laser therapy reduces pain sensation (Millis et al., 2005; Millis and Levine, 2014). Although the exact mechanism is still unclear, two theories have been proposed. The first theory postulates a release of endorphins and enkephalins (Millis et al., 2005; Mil- 
lis and Levine, 2014). The second theory is based on two studies in rats, where laser therapy induced an inhibitory effect on the conduction of peripheral nerves by inhibiting peripheral nociceptors (Tsuchiya et al., 1994; Wedlock et al., 1996; Wedlock and Shephard, 1996; Chow et al., 2011; Yan et al., 2011).

Laser therapy has also been studied in nerve revalidation with positive effect as well in rat models and in a dog model. This effect was seen in both the acute post-traumatic stage and the more chronic cases of nerve injury. Laser therapy resulted in better functional activity, less scar tissue, decreased degeneration of motor neurons and increased myelinization and axonal growth. In the dog study, the spinal cord was transected and replaced with a graft. All dogs that received laser therapy walked after nine weeks, while the other dogs remained paralyzed (Rochkind et al., 1986; Rochkind et al., 1987; Shamir et al., 2001; Shin et al., 2003; Rochkind, 2004).

In a study by Draper et al. (2012), the effect of LLLT on the revalidation of T3-L3 disk herniation was investigated in 36 dogs. All dogs underwent hemi-laminectomy. Eighteen of them had additional laser therapy of the affected region for about five days after surgery. The time to regain mobility of the dogs that received LLLT was three to five days, which was significantly lower than for the dogs that only received surgery (about 14 days). This led to the conclusion that LLLT is beneficial in the revalidation of disk herniation patients (Draper et al., 2012).

LLLT might have benefits on other tissues and conditions, such as tendons, ligaments and osteoarthritis. Although several studies have been performed in human medicine, scientific veterinary literature on this subject is not available for the moment (Millis and Levine, 2014).

Because LLLT uses both visible and invisible light, protective eyewear is required. Heat generated by laser light may damage the retina. Therefore, caution should be taken while operating the laser and treating tissues in the region of the eyes. For the same reason, laser should not be used over growth plates, malignancies and in pregnant patients (Millis and Levine, 2014; Prydie and Hewitt, 2015).

\section{Other modalities}

Over the last years, a static or electromagnetic field has been advocated to be beneficial in revalidation therapy. The main focus of this modality is (OA) pain reduction, although it is claimed to have some positive effects on wound and bone healing as well (Millis and Levine, 2014).

Evidence to support these statements are scarce to absent. The limited proof that may be found in the literature is often based on a single study with a limited number of patients (Khanaovitz et al., 1994; Scardino et al., 1998; Sullivan et al., 2013).

Before considering this therapy as a standalone treatment, more peer-reviewed, well-designed studies are needed.

\section{THERAPEUTIC EXERCISES}

Exercise is an important factor in rehabilitation. Passive movement and modalities are a great aid, but natural muscle stimulation is still the best way to exercise muscles. A good physio-therapeutic protocol should therefore be composed out of a combination of manual therapy, modalities and therapeutic exercises (Bockstahler et al., 2004).

It is not the objective of this review to discuss every type of exercise. These are well-described in the literature (Bockstahler et al., 2004; Sharp, 2008; Millis and Levine, 2014; Prydie and Hewitt, 2015).

Therapeutic exercises can be divided into three groups: passive, assisted and active exercises. The best known therapeutic exercise is hydrotherapy, which will be discussed more extensively.

\section{Passive exercises}

These are exercises in which the animal does not actively use its own muscles. Examples are passive range of motion (pROM) and stretching exercises. The goal of these exercises is to facilitate the joints ROM and soft tissues flexibility (Bockstahler et al., 2004).

Several studies have indicated that PROM exercises following shortly after injury or surgery has a beneficial effect on the desired outcome (Olson, 1987; Schollmeier et al., 1994; Schollmeier et al., 1996; Millis et al., 1997; Crook et al., 2007; Jandi and Schulman, 2007).

\section{Assisted exercises}

In these exercises, the animals use their own muscle strength, while being supported by an aid or by a physiotherapist (Figure 8). These exercises are useful in

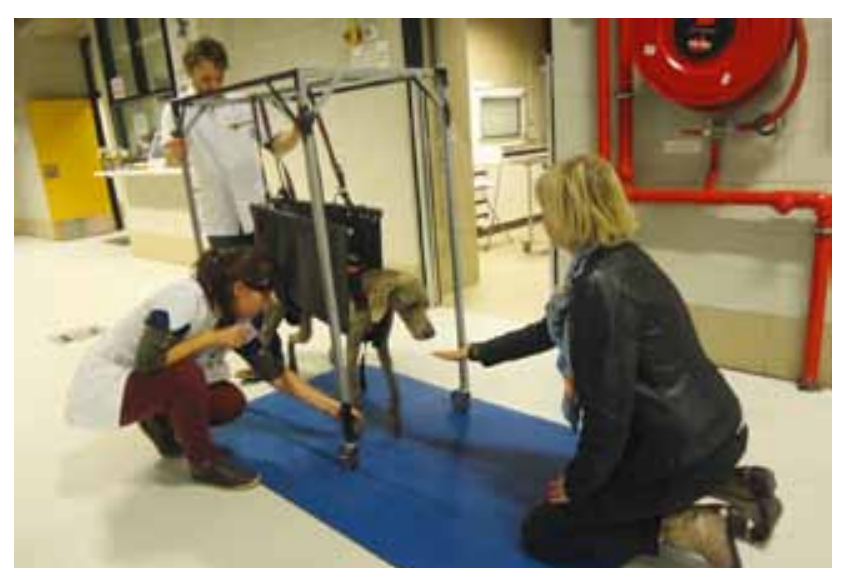

Figure 8. Assisted walking device used in a dog with surgically treated Wobbler's syndrome. 


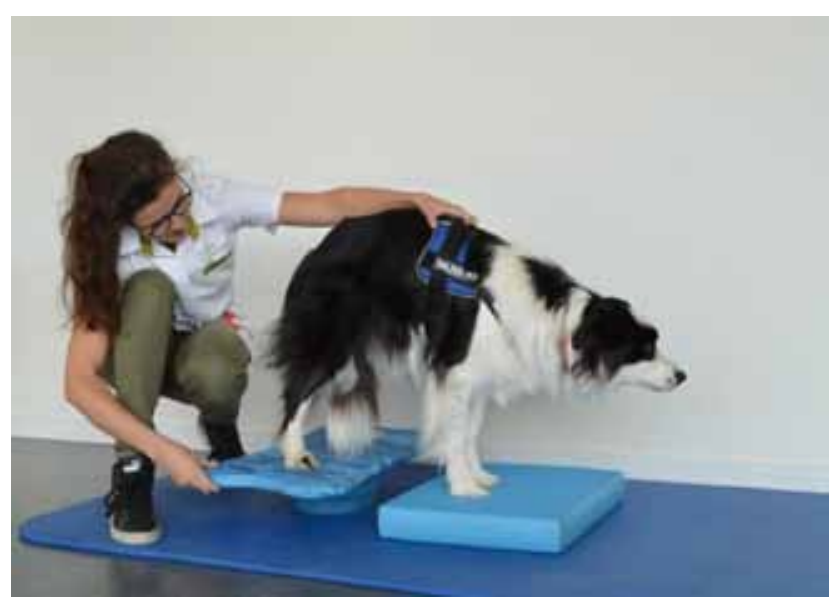

Figure 9. Balance board exercise.

weight bearing and proprioceptive training (Bockstahler et al., 2004). An example is balance board exercises (Figure 9).

\section{Active exercises}

Animals perform exercises using only their own muscle strength without any assistance. Known examples are Cavaletti rails and aquatic therapy (Bockstahler et al., 2004) (Figure 10).

\section{Aquatic therapy}

One of the most popular exercises in veterinary physiotherapy is aquatic therapy. The reason for its success can be found in the properties of water:

\section{Relative density}

Relative density stands for the ratio of the weight of an object, relative to the weight of an equal amount of water (Haralson, 1986). It determines whether an object will either float or sink in the water. Density of an object is expressed in an exact number known as the 'specific gravity'. The specific gravity of water is 1 (Hecox et al., 1994). This means that if the ratio of the specific gravity of an object to water is more than 1 , the object will have the tendency to sink, whereas objects with a ratio of less than 1 will have the tendency to float.

The specific gravity also determines which volume of the object will be submerged. For example, an object with a specific gravity of 0.95 will be submerged for $95 \%$, while $5 \%$ will float above the surface (Hecox et al., 1994).

\section{Buoyance}

This is the upward thrust of water acting on a body that creates an apparent decrease in the weight of a body while immersed (Hecox et al., 1994). A study in dogs demonstrated that the weight borne immersed in water relative to the weight on the ground was

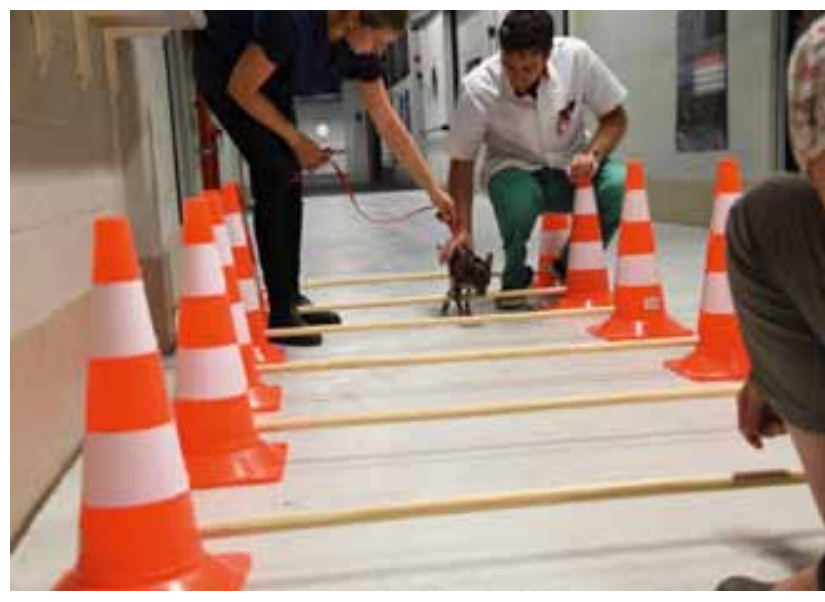

Figure 10. Cavaletti rail.

$91 \%$ when the water reached the level of the tibial malleoli, $85 \%$ when the level reached the femoral condyles, and $38 \%$ when the water reached the level of the greater trochanter of the femur (Levine et al., 2010). This results in more comfortable movements with less pain (Bockstahler et al., 2004). Buoyance together with the viscosity also assists in stabilizing less stable dogs, for example in cases of paresis or obesity (Millis and Levine, 2014).

\section{Hydrostatic pressure}

At a given depth, the pressure exerted by a liquid on a body is equally divided on all surfaces of that body, i.e. Pascal's law (Polyanin and Chernoutsan, 2010). Consequently, the deeper the body is submerged in the water, the higher the pressure on the body. This might facilitate movements with less pain and reduce edema and swelling (Millis and Levine, 2014).

\section{Viscosity}

Molecules in a liquid have higher cohesive forces than the molecules in a gas. Therefore, the resistance to move in a liquid, such as water, is higher than the resistance to move in air (Geigle et al., 1997). Exercising in water therefore stimulates the muscle function and cardiovascular fitness (Millis and Levine, 2014).

Studies in human medicine have demonstrated a

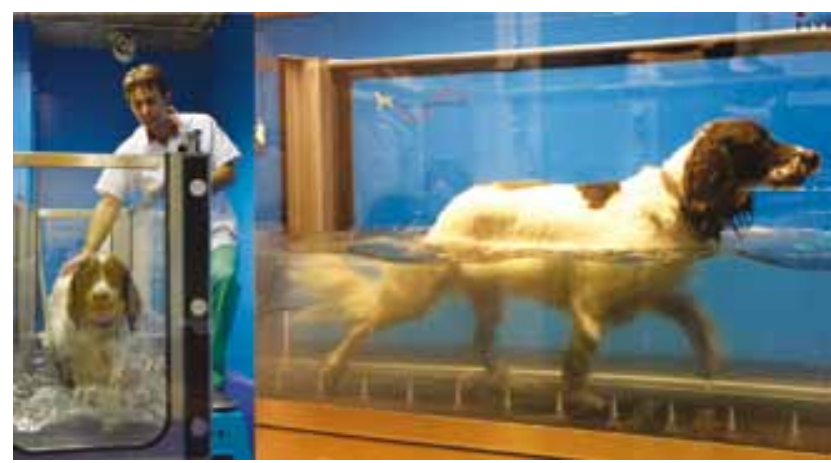

Figure 11. Underwater treadmill for dogs. 
positive effect on muscle strength, muscle endurance cardiorespiratory endurance, agility and ROM combined with a reduction in pain (Whitley and Schoene, 1987; Speer et al., 1993; Millis and Levine, 2014). In veterinary medicine, studies are limited. One study has demonstrated an increased ROM after swimming in dogs with a surgically treated cruciate ligament rupture. These dogs also showed an 18.5\% higher peak vertical force than dogs that had no post-operative hydrotherapy (Marsolais et al., 2003).

A recent study has demonstrated that hydrotherapy has a beneficial effect on inflammatory biomarkers in dogs. Fifty-five dogs were divided into three groups: healthy dogs without hydrotherapy, dogs with hip OA with hydrotherapy, healthy dogs with hydrotherapy. The dogs were allowed to swim for twenty minutes three times a day for an eight-weeks period. Every two weeks, blood samples were collected to determine specific OA biomarkers. Starting from six weeks, OA dogs showed less pain on clinical examination and there was a significant change in biomarkers. It was concluded that swimming is beneficial for the treatment of dogs with hip OA (Nganvongpanit et al., 2014).

In small animal rehabilitation, aquatic therapy is performed either in a pool or in an underwater treadmill. An underwater treadmill allows a better control of the treatment goals by altering the height of the water and the speed of motion. No life vest is required, although support might be useful when the animals are still slightly unstable in their movement. When necessary, the physiotherapist can enter the treadmill along with the dog (Figure 11).

A pool requires more space and life vests for the patient. The physiotherapist is always required to enter the pool with the dog. A treadmill can be incorporated into the pool.

Hydrotherapy may be used in some stadia of the rehabilitation of nearly all conditions. Because of its influence on musculature and the cardiovascular system, aquatic therapy also helps in training healthy dogs to improve their general condition (Millis and Levine, 2014).

\section{CONCLUSIONS}

Animal physiotherapy is to be considered in every orthopedic or neurological condition that causes pain and/or discomfort or dysfunction. Most of the techniques are based on human studies and more recently, some veterinary studies have been published. Because of the versatility of therapy, it is not always easy to attribute clinical progression exclusively to one technique in physiotherapy (or even to physiotherapy itself). Based on the current literature, it can be concluded that there are strong indications that physiotherapy aids in the rehabilitation of clinical patients, whether it is used as pain relief or for intense mobility revalidation.

\section{LITERATURE}

Akai M., Usuba M., Maeshima T., Shirasaki Y., Yasuoka S. (1997). Laser's effect on bone and cartilage change induced by joint immobilization: An experiment with animal model. Lasers in Surgery and Medicine 21, 480-484

Anderson A. F., Lipscomb A. B. (1989). Analysis of rehabilitation techniques after anterior cruciate reconstruction. The American Journal of Sports Medicine 17, 154-160

Aure O. F., Nilsen J. H., Vasseljen O. (2003). Manual therapy and exercise therapy in patients with chronic low back pain: a randomized, controlled trial with 1-year followup. Spine (Phila Pa 1976) 28, 525-532

Batista J. D., Sargenti-Neto S., Dechichi P., Rocha F. S., Pagnoncelli R. M. (2015). Low-level laser therapy on bone repair: is there any effect outside the irradiated field? Lasers in Medical Science 30, 1569-1574

Bayat M., Ansari A., Hekmat H. (2004). Effect of low-power helium-neon laser irradiation on 13-week immobilized articular cartilage of rabbits. Indian Journal of Experimental Biology 42, 866-870

Bockstahler B., Levine D., Millis D. L., Wandrey S. O. N. 2004. In: B. Egner (editor). Essential Facts of Physiotherapy in Dogs and Cats: Rehabilitation and Pain Management : a Reference Guide with DVD. 1st Edition, BE Vet Verlag, Babenhausen.

Bocobo C., Fast A., Kingery W., Kaplan M. (1991). The effect of ice on intra-articular temperature in the knee of the dog. American Journal of Physical Medicine and Rehabilitation 70, 181-185

Braverman B., Mccarthy R. J., Ivankovich A. D., Forde D. E., Overfield M., Bapna M. S. (1989). Effect of heliumneon and infrared-laser irradiation on wound-healing in rabbits. Lasers in Surgery and Medicine 9, 50-58

Chow R., Armati P., Laakso E. L., Bjordal J. M., Baxter G. D. (2011). Inhibitory effects of laser irradiation on peripheral mammalian nerves and relevance to analgesic effects: A systematic review. Photomedicine and Laser Surgery 29, 365-381

Crook T., McGowan C., Pead M. (2007). Effect of passive stretching on the range of motion of osteoarthritic joints in 10 labrador retrievers. Veterinary Record 160, 545-547

Dahlberg J., Fitch G., Evans R. B., McClure S. R., Conzemius M. (2005). The evaluation of extracorporeal shockwave therapy in naturally occurring osteoarthritis of the stifle joint in dogs. Veterinary and Comparative Orthopaedics and Traumatology 18, 147-152

de Sousa V. L., de Alvarenga J., Filho J. G. P., Canola J. C., Ferrigno C. R. A., Alves J. M., Duarte L. R. (2008). Low-intensity pulsed ultrasound in diaphyseal fractures: clinical application in dogs. Ciencia Rural 38, 1030-1037

Denis M., Moffet H., Caron F., Ouellet D., Paquet J., Nolet L. (2006). Effectiveness of continuous passive motion and conventional physical therapy after total knee arthroplasty: a randomized clinical trial. Physical Therapy 86, 174-185

Dias R. C., Dias J. M., Ramos L. R. (2003). Impact of an exercise and walking protocol on quality of life for elderly people with OA of the knee. Physiotherapy Research International 8, 121-130

Diong J., Allen N. and Sherrington C. (2016). Structured exercise improves mobility after hip fracture: a metaanalysis with meta-regression. British Journal of Sports Medicine 50, 346-355

Draper W. E., Schubert T. A., Clemmons R. M., Miles S. A. 
(2012). Low-level laser therapy reduces time to ambulation in dogs after hemilaminectomy: a preliminary study. Journal of Small Animal Practice 53, 465-469

Drygas K. A., McClure S. R., Goring R. L., Pozzi A., Robertson S. A., Wang C. (2011). Effect of cold compression therapy on postoperative pain, swelling, range of motion, and lameness after tibial plateau leveling osteotomy in dogs. Journal of the American Veterinary Medical Association 238, 1284-1291

Dyson M., Pond J. B., Joseph J. and Warwick R. (1968). The stimulation of tissue regeneration by means of ultrasound. Clinical Science 35, 273-285

Esnouf A., Wright P. A., Moore J. C., Ahmed S. (2007). Depth of penetration of an 850nm wavelength low level laser in human skin. Acupuncture \& Electro-Therapeutics Research 32, 81-86

Favaro-Pipi E., Bossini P., de Oliveira P., Ribeiro J. U., Tim C., Parizotto N. A., Alves J. M., Ribeiro D. A., de Araujo H. S. S., Renno A. C. M. (2010). Low-intensity pulsed ultrasound produced an increase of osteogenic genes expression during the process of bone healing in rats. Ultrasound in Medicine and Biology 36, 2057-2064

Fox S. M. (2013). Functional physiology of pain. In: D. B. Fox (editor). Pain Management in Small Animal Medicine. First edition, CRC Press, Boca Raton, p. 47 - 90.

Gallagher A., Cross A. R., Sepulveda G. (2012). The effect of shock wave therapy on patellar ligament desmitis after tibial plateau leveling osteotomy. Veterinary Surgery 41, 482-485

Geigle P. R., Cheek W. L., Gould M. L., Hunt H. C., Shafic B. (1997). Aquatic physical therapy for balance: the interaction of somatosensory and hydrodynamic principles. Journal of Aquatic Physical Therapy 5, 7

Gerbi M. E. M., Marques A. M. C., Ramalho L. M. P., Ponzi E. A. C., Carvalho C. M., Santos R. D. C., Oliveira P. C., Noia M., Pinheiro A. L. B. (2008). Infrared laser light further improves bone healing when associated with bone morphogenic proteins: An in vivo study in a rodent model. Photomedicine and Laser Surgery 26, 55-60

Guzzardella G. A., Morrone G., Torricelli P., Rocca M., Tigani D., Brodano G. B., Ferrari D., Fini M., Giardino R. (2000). Assessment of low-power laser biostimulation on chondral lesions: An "in vivo" experimental study. Artificial Cells Blood Substitutes and Immobilization Biotechnology 28, 441-449

Guzzardella G. A., Tigani D., Torricelli P., Fini M., Martini L., Morrone G., Giardino R. (2001). Low-power diode laser stimulation of surgical osteochondral defects: Results after 24 weeks. Artificial Cells Blood Substitutes and Immobilization Biotechnology 29, 235-244

Haralson K. (1986). Therapeutic pool programs. Journal of Clinical Outcome Management 5, 7

Hecox B., Mehreteab T. A., Weisberg J. (1994). In: B. Hecox, T. A. Mehreteab, J. Weisberg (editors). Physical Agents: A Comprehensive Text for Physical Therapists. First edition, Appleton \& Lange, East Norwalk, Conn.

Hertling D., Kessler R. M. (2006). In: D. J. Payne, A. P. Williams (editors). Management of Common Musculoskeletal Disorders: Physical Therapy Principles and Methods. Fourth edition, Lippincott Williams \& Wilkins, Philadelphia.

Jandi A. S., Schulman A. J. (2007). Incidence of motion loss of the stifle joint in dogs with naturally occurring cranial cruciate ligament rupture surgically treated with tibial plateau leveling osteotomy: Longitudinal clinical study of 412 cases. Veterinary Surgery 36, 114-121
Johnson J. M., Johnson A. L., Pijanowski G. J., Kneller S. K., Schaeffer D. J., Eurell J. A., Smith C. W., Swan K. S. (1997). Rehabilitation of dogs with surgically treated cranial cruciate ligament-deficient stifles by use of electrical stimulation of muscles. American Journal of Veterinary Research 58, 1473-1478

Kathmann I., Cizinauskas S., Doherr M. G., Steffen F., Jaggy A. (2006). Daily controlled physiotherapy increases survival time in dogs with suspected degenerative myelopathy. Journal of Veterinary Internal Medicine 20, 927-932

Khanaovitz N., Arnoczky S. P., Nemzek J., Shores A. (1994). The effect of electromagnetic pulsing on posterior lumbar spinal fusions in dogs. Spine 19, 705-709

Kieves N. R., MacKay C. S., Adducci K., Rao S., Goh C., Palmer R. H., Duerr F. M. (2015). High energy focused shock wave therapy accelerates bone healing A blinded, prospective, randomized canine clinical trial. Veterinary and Comparative Orthopaedics and Traumatology 28, 425-432

Kolarova H., Ditrichova D., Wagner J. (1999). Penetration of the laser light into the skin in vitro. Lasers in Surgery and Medicine 24, 231-235

Kristiansen T. K., Ryaby J. P., McCabe J., Frey J. J., Roe L. R. (1997). Accelerated healing of distal radial fractures with the use of specific, low-intensity ultrasound. A multicenter, prospective, randomized, double-blind, placebo-controlled study. Journal of Bone and Joint Surgery. American Volume 79, 961-73

Landrum E. L., Kelln C. B., Parente W. R., Ingersoll C. D., Hertel J. (2008). immediate effects of anterior-to-posterior talocrural joint mobilization after prolonged ankle immobilization: a preliminary study. Journal of Manual and Manipulative Therapy 16, 100-105

Levine D., Marcellin-Little D. J., Millis D. L., Tragauer V., Vet M. M., Osborne J. A. (2010). Effects of partial immersion in water on vertical ground reaction forces and weight distribution in dogs. American Journal of Veterinary Research 71, 1413-1416

Levine D., Millis D. (2002). The effect of TENS on osteoarthritic pain in the stifle of dogs. In: Proceedings of the Second International Symposium on Rehabilitation and Physical Therapy in Veterinary Medicine 14, Knoxville, TN,

Levine D., Millis D. L., Marcellin-Little D. J. (2005). Introduction to veterinary physical rehabilitation. Veterinary Clinics of North America. Small Animal Practice 35, 1247-1254, vii

Levine D., Millis D. L., Mynatt T. (2001). Effects of 3.3$\mathrm{MHz}$ ultrasound on caudal thigh muscle temperature in dogs. Veterinary Surgery 30, 170-174

Lirani-Galvao A. P., Jorgetti V., da Silva O. L. (2006). Comparative study of how low-level laser therapy and low-intensity pulsed ultrasound affect bone repair in rats. Photomedicine and Laser Surgery 24, 735-740

Loonam J. E., Millis D., Stevens M. (2003). The effect of therapeutic ultrasound on tendon healing and extensibility. In: Proceedings of the 30th Veterinary Orthopedic Society, Steamboat Springs, Colorado, 69

Marsolais G. S., McLean S., Derrick T., Conzemius M. G. (2003). Kinematic analysis of the hind limb during swimming and walking in healthy dogs and dogs with surgically corrected cranial cruciate ligament rupture. Journal of the American Veterinary Medical Association 222, 739-743

Maxwell L. (1992). Therapeutic ultrasound: its effects on 
the cellular and molecular mechanisms of inflammation and repair. Physiotherapy 78, 421-426

Melzack R., Wall P. D. (1965). Pain mechanisms - a new theory. Science 150, 971-979

Michlovitz S. L. (1996). In: S. L. Michlovitz (editor). Thermal Agents in Rehabilitation. Third edition, F.A. Davis, Philadelphia.

Millard R. P., Towle-Millard H. A., Rankin D. C., Roush J. K. (2013). Effect of cold compress application on tissue temperature in healthy dogs. American Journal of Veterinary Research 74, 443-447

Millard R. P., Towle-Millard H. A., Rankin D. C., Roush J. K. (2013). Effect of warm compress application on tissue temperature in healthy dogs. American Journal of Veterinary Research 74, 448-451

Millis D., Drum M., Whitlock D. (2011). Complementary use of extracorporeal Shock Wave therapy on elbow osteoarthritis in dogs. In: March 5th- 12th, Snowmass, Colorado, USA.

Millis D., Levine A. D., Brumlow M., Weigel J. P. (1997). Scientific presentation abstracts: the seventh annual american college of veterinary surgeons symposium October 1997, Orlando, FL. Veterinary Surgery 26, 408-435

Millis D., Levine D. (2014). In: D. Millis, D. Levine (editors). Canine Rehabilitation and Physical Therapy. Second edition, Elsevier Health Sciences, Philadelphia.

Millis D. L. (2004). Getting the dog moving after surgery. Journal of the American Animal Hospital Association 40, 429-436

Millis D. L., Francis D., Adamson C. (2005). Emerging modalities in veterinary rehabilitation. Veterinary Clinics of North America-Small Animal Practice 35, 1335 -1355

Mlacnik E., Bockstahler B. A., Muller M., Tetrick M. A., Nap R. C., Zentek J. (2006). Effects of caloric restriction and a moderate or intense physiotherapy program for treatment of lameness in overweight dogs with osteoarthritis. Journal of the American Veterinary Medical Association 229, 1756-1760

Moffet H., Collet J. P., Shapiro S. H., Paradis G., Marquis F., Roy L. (2004). Effectiveness of intensive rehabilitation on functional ability and quality of life after first total knee arthroplasty: A single-blind randomized controlled trial. Archives of Physical Medicine and Rehabilitation 85, 546-556

Morrone G., Guzzardella G. A., Torricelli P., Rocca M., Tigani D., Brodano G. B., Fini M., Giardino R. (2000). Osteochondral lesion repair of the knee in the rabbit after low-power diode Ga-Al-As laser biostimulation: An experimental study. Artificial Cells Blood Substitutes and Immobilization Biotechnology 28, 321-336

Mosselmans L. (2011). Het effect van ultrageluid op botheling bij de hond. Pilootstudie uitgevoerd bij 5 honden. Department of Medical Imaging and Small Animal Orthopedics, Ghent University, Ghent.

Mosselmans L., Samoy Y., Verleyen P., Herbots P., Van Ryssen B. (2013). Applications of ultrasound in veterinary medicine. Vlaams Diergeneeskundig Tijdschrift 82, 103-111

Mueller M., Bockstahler B., Skalicky M., Mlacnik E. and Lorinson D. (2007). Effects of radial shockwave therapy on the limb function of dogs with hip osteoarthritis. Veterinary Record 160, 762-765

Nganvongpanit K., Tanvisut S., Yano T., Kongtawelert P. (2014). Effect of swimming on clinical functional parameters and serum biomarkers in healthy and osteo- arthritic dogs. International Scholarly Research Notices: Veterinary Sciences, 459809

Olson J. E., Stravino V. D. (1972). A review of cryotherapy. Physical Therapy 52, 840-853

Olson V. L. (1987). Evaluation of joint mobilization treatment - a method. Physical Therapy 67, 351-356

Ostelo R. W., Costa L. O., Maher C. G., de Vet H. C., van Tulder M. W. (2009). Rehabilitation after lumbar disc surgery: an update Cochrane review. Spine (Phila $\mathrm{Pa}$ 1976) $34,1839-1848$

Ostelo R. W., de Vet H. C., Waddell G., Kerckhoffs M. R., Leffers P., van Tulder M. (2003). Rehabilitation following first-time lumbar disc surgery: a systematic review within the framework of the cochrane collaboration Spine (Phila Pa 1976) 28, 209-218

Peplow P. V., Chung T. Y., Baxter G. D. (2010). Laser photobiomodulation of wound healing: a review of experimental studies in mouse and rat animal models. Photomedicine and Laser Surgery 28, 291-325

Pinheiro A. L. B., Oliveira M. G., Martins P. P. M., Ramalho L. M. P., Oliveira M. A. M. d., Júnior A. N., Nicolau R. A. (2000). Biomodulatory effects of LLLT on bone regeneration. Laser Therapy 13, 73-79

Polyanin A. D., Chernoutsan A. I. (2010). E4 Hydrodynamics. In: A. D. Polyanin and A. I. Chernoutsan (editors). A Concise Handbook of Mathematics, Physics, and Engineering Sciences. 1st ed., CRC Press, Boca Raton, p. 773.

Prydie D., Hewitt I. (2015). In: D. Prydie, I. Hewitt (editors). Practical Physiotherapy for Small Animal Practice. First edition, Wiley, Chichester.

Queiroga A. S., Sousa F. B., Araujo J. M. S., Santos S. D., Sousa C. D. S., Quintans T. C., Almeida T. P., Nonaka C. F. W., Batista L. V. and Limeira F. A. (2008). Evaluation of bone repair in the femur of rats submitted to laser therapy in different wavelengths: An image segmentation method of analysis. Laser Physics 18, 1087-1091

Rantanen J., Thorsson O., Wollmer P., Hurme T., Kalimo H. (1999). Effects of therapeutic ultrasound on the regeneration of skeletal myofibers after experimental muscle. American Journal of Sports Medicine 27, 54-59

Rawool N. M., Goldberg B. B., Forsberg F., Winder A. A., Hume E. (2003). Power Doppler assessment of vascular changes during fracture treatment with low-intensity ultrasound. Journal of Ultrasound in Medicine 22, 145-153

Rexing J., Dunning D., Siegel A. M., Knap K., Werbe B. (2010). Effects of cold compression, bandaging, and microcurrent electrical therapy after cranial cruciate ligament repair in dogs. Veterinary Surgery 39, 54-58

Rezende S. B., Ribeiro M. S., Nunez S. C., Garcia V. G., Maldonado E. P. (2007). Effects of a single near-infrared laser treatment on cutaneous wound healing: Biometrical and histological study in rats. Journal of Photochemistry and Photobiology B-Biology 87, 145-153

Rochkind S. (2004). The role of laser phototherapy in nerve tissue regeneration and repair: research development with perspective for clinical application. Saõ Paulo, Brazil, 94-95

Rochkind S., Barrnea L., Razon N., Bartal A., Schwartz M. (1987). Stimulatory effect of he-ne low-dose laser on injured sciatic-nerves of rats. Neurosurgery 20, 843-847

Rochkind S., Nissan M., Razon N., Schwartz M., Bartal A. (1986). Electrophysiological effect of hene laser on normal and injured sciatic-nerve in the rat. Acta Neurochirurgica $83,125-130$ 
Rodrigues M. E. S., Kodama A. C., Rollo J. M. D. A., Nascimento A. P. C., Malosso T. G. (2004). Low-intensity pulsed ultrasound effects on a bone model of ovariectomized female rats. Osteoporosis International 15, 117

Saunders D. G., Walker J. R., Levine D. (2005). Joint mobilization. Veterinary Clinics of North America-Small Animal Practice 35, 1287-1316

Scardino M. S., Swaim S. F., Sartin E. A., Steiss J. E., Spano J. S., Hoffman C. E., Coolman S. L., Peppin B. L. (1998). Evaluation of treatment with a pulsed electromagnetic field on wound healing, clinicopathologic variables, and central nervous system activity of dogs. American Journal of Veterinary Research 59, 1177-1181

Schollmeier G., Sarkar K., Fukuhara K., Uhthoff H. K. (1996). Structural and functional changes in the canine shoulder after cessation of immobilization. Clinical Orthopaedics and Related Research 310-315

Schollmeier G., Uhthoff H. K., Sarkar K., Fukuhara K. (1994). Effects of immobilization on the capsule of the canine glenohumeral joint - a structural-functional study. Clinical Orthopaedics and Related Research 37-42

Schortinghuis J., Ruben J. L., Raghoebar G. M., Stegenga B. (2004). Ultrasound to stimulate mandibular bone defect healing: A placebo-controlled single-blind study in rats. Journal of Oral and Maxillofacial Surgery 62, 194201

Shamir M. H., Rochkind S., Sandbank J., Alon M. (2001). Double-blind randomized study evaluating regeneration of the rat transected sciatic nerve after suturing and postoperative low-power laser treatment. Journal of Reconstructive Microsurgery 17, 133-137

Sharp B. (2008). Physiotherapy in small animal practice. In Practice 30, 190-199

Shelbourne K. D., Nitz P. (1990). Accelerated rehabilitation after anterior cruciate ligament reconstruction. American Journal of Sports Medicine 18, 292-299

Shelbourne K. D., Wilckens J. H., Mollabashy A., DeCarlo M. (1991). Arthrofibrosis in acute anterior cruciate ligament reconstruction: The effect of timing of reconstruction and rehabilitation. The American Journal of Sports Medicine 19, 332-336

Sherrington C., Lord S. R. (1997). Home exercise to improve strength and walking velocity after hip fracture: a randomized controlled trial. Archives of Physical Medicine and Rehabilitation 78, 208-212

Shin D. H., Lee E., Hyun J. K., Lee S. J., Chang Y. P., Kim J. W., Choi Y. S., Kwon B. S. (2003). Growth-associated protein-43 is elevated in the injured rat sciatic nerve after low power laser irradiation. Neuroscience Letters 344, $71-74$

Speer K. P., Cavanaugh J. T., Warren R. F., Day L. and Wickiewicz T. L. (1993). A Role for Hydrotherapy in Shoulder Rehabilitation. American Journal of Sports Medicine $21,850-853$
Steiss J. E., Levine D. (2005). Physical agent modalities. Veterinary Clinics of North America-Small Animal Practice 35, 1317-1333

Sullivan M. O., Gordon-Evans W. J., Knap K. E., Evans R. B. (2013). Randomized, controlled clinical trial evaluating the efficacy of pulsed signal therapy in dogs with osteoarthritis. Veterinary Surgery 42, 250-254

Tanzer M., Kantor S., Bobyn J. D. (2001). Enhancement of bone growth into porous intramedullary implants using non-invasive low intensity ultrasound. Journal of Orthopaedic Research 19, 195-199

Toy E., Ozturk F., Altindis S., Kozacioglu S., Toy H. (2014). Effects of low-intensity pulsed ultrasound on bone formation after the expansion of the inter-premaxillary suture in rats: a histologic and immunohistochemical study. Australian Orthodontic Journal 30, 176-183

Tsuchiya K., Kawatani M., Takeshige C., Matsumoto I. (1994). Laser irradiation abates neuronal responses to nociceptive stimulation of rat-paw skin. Brain Research Bulletin 34, 369-374

Wakim K. G., Porter A. N., Krusen F. H. (1951). Influence of physical agents and of certain drugs on intra-articular temperature. Archives of Physical Medicine and Rehabilitation 32, 714-721

Wedlock P., Shephard R. A., Little C., McBurney F. (1996). Analgesic effects of cranial laser treatment in two rat nociception models. Physiology \& Behavior 59, 445-448

Wedlock P. M., Shephard R. A. (1996). Cranial irradiation with GaAlAs laser leads to naloxone reversible analgesia in rats. Psychological Reports 78, 727-731

Whitley J. D., Schoene L. L. (1987). Comparison of heartrate responses - water walking versus treadmill walking. Physical Therapy 67, 1501-1504

Yan W. X., Chow R., Armati P. J. (2011). Inhibitory effects of visible $650-\mathrm{nm}$ and infrared $808-\mathrm{nm}$ laser irradiation on somatosensory and compound muscle action potentials in rat sciatic nerve: implications for laser-induced analgesia. Journal of the Peripheral Nervous System 16, 130-135

Zeilhofer H. U., Wildner H., Yevenes G. E. (2012). Fast synaptic inhibition in spinal sensory processing and pain control. Physiological Reviews 92, 193-235

Zink M. C., Van Dyke J. B. 2013. In: M. C. Zink, J. B. Van Dyke (editors). Canine Sports Medicine and Rehabilitation. First edition, Wiley, Iowa.

Zorlu U., Tercan M., Ozyazgan I., Taskan I., Kardas Y., Balkar F., Ozturk F. (1998). Comparative study of the effect of ultrasound and electrostimulation on bone healing in rats. American Journal of Physical Medicine \& Rehabilitation 77, 427-432

Zusman M. (2010). There's something about passive movement. Medical Hypotheses 75, 106-110 